\title{
Thank you from HMPG and the editors
}

\section{SAMJ reviewers}

HMPG and the editors of SAMJ would like to thank all who participated in the peer review process during 2018. We are grateful for the expertise, insight and thoughtful critiques shared with our authors through the review process, and without which maintaining the high standard of our journal would be impossible.

We apologise if any individual reviewer has inadvertently been excluded, and to those reviewers who were recruited after this issue was published.

Miriam Adhikari, University of KwaZulu-Natal

Simon Akerman, Grey's Hospital, Pietermaritzburg

Saeed Akhtar, Kuwait University

Nazeer Alli, National Health Laboratory Service

Elize Archer, Stellenbosch University

Affirul Ariffin, Universiti Sains Islam Malaysia

Olalekun Ayo-Yusuf, Sefako Makgatho Health Sciences University

Colleen Bamford, National Health Laboratory Service

Varsha Bangalee, University of KwaZulu-Natal

Whitney Barnett, University of Cape Town

Satish Bhagwanjee, University of Washington

Arvin Bhana, South African Medical Research Council

Tihana Bicanic, University of London

Julia Blitz, Stellenbosch University

Marc Blockman, University of Cape Town

Adam Boutall, UCT Private Academic Hospital

Tom Boyles, University of Cape Town

Eckhart Buchmann, University of the Witwatersrand

Eileen Burd, Emory University

Neil Cameron, Stellenbosch University

Alain Chichom-Mefire, University of Buea

Damian Clarke, University of KwaZulu-Natal

Peter Cleaton-Jones, University of the Witwatersrand

Edward Coetzee, University of Cape Town

Melissa Cooke, University of Cape Town

Ian Cooper, Stellenbosch University

Graeme Copley, Red Cross War Memorial Children's Hospital

Mark Cotton, Stellenbosch University

Joel Dave, Groote Schuur Hospital

Justine Davies, King's College London

Halima Dawood, Grey's Hospital

Rik De Decker, University of Cape Town

Tobie de Villiers, Stellenbosch University

Eric Decloedt, Stellenbosch University

Daan den Hollander, University of KwaZulu-Natal

Larry Distiller, Centre for Diabetes and Endocrinology

Robert Dunn, University of Cape Town

Robert Dyer, University of Cape Town

Brian Eley, Red Cross War Memorial Children's Hospital

Charlene Elliott, University of Calgary

Zane Farina, University of KwaZulu-Natal

Sue Fawcus, University of Cape Town

Shinga Feresu, University of Pretoria

Greg Firth, University of the Witwatersrand

Nathan Ford, World Health Organization

Kevin Fourie, Forensic Pathology Services, Department of Health

Gabriel Gebhardt, Stellenbosch University

Ameena Goga, South African Medical Research Council
Nicole Goldstein, University of the Witwatersrand Chetna Govind, Lancet Laboratories

Diane Gray, University of Cape Town

Robin Green, University of Pretoria

Andrew Grieve, University of the Witwatersrand

Lyn Horn, University of Cape Town

Gillian Hunt, National Institute for Communicable Diseases

Kathy Jacobsen, George Mason University

Louis Jenkins, Stellenbosch University

Eduard Jonas, University of Cape Town

Portia Jordan, Nelson Mandela Metropolitan University

Gavin Joynt, Chinese University of Hong Kong

Ben Jugmohan, University of the Witwatersrand

Ismail Kalla, University of the Witwatersrand

Shuaib Kauchali, University of KwaZulu-Natal

Mpho Kgomo, University of Pretoria

Sophia Kisting, National Health Laboratory Service

Sharon Kling, Stellenbosch University

Christo Kloppers, University of Cape Town

Judy Kluge, Stellenbosch University

Steve Koch, University of Pretoria

Zach Koto, Sefako Makgatho Health Sciences University

Amanda Krause, National Health Laboratory Service

Sa'ad Laahri, Khayelitsha Hospital

Melodie Labuschaigne, University of South Africa

John Lazarus, University of Cape Town

Richard Lessells, London School of Hygiene and Tropical Medicine

Johnathan Levin, University of the Witwatersrand

Hennie Lombaard, Rahima Moosa Mother and Child Hospital

Leslie London, University of Cape Town

Vernon Louw, University of Cape Town

Mzubanzi Mabongo, University of the Witwatersrand

Honey Mabuza, Sefako Makgatho Health Sciences University

Judith Mackay, World Lung Foundation

Nomandla Madala, Sefako Makgatho Health Sciences University

Ozayr Mahomed, University of KwaZulu-Natal

Safia Mahomed, University of South Africa

Zeyn Mahomed, University of the Witwatersrand

Jacques Le Roux Malherbe, University of the Free State

Relebogile Mapuroma, University of the Witwatersrand

Dipuo Masage, University of the Witwatersrand

Refiloe Masekela, University of KwaZulu-Natal

Felistas Mashinya, University of Limpopo

Christina Matthews, South African Medical Research Council

Amam Mbakwem, University of Lagos

David McQuoid-Mason, University of KwaZulu-Natal

Peter Millard, University of New England

Rosie Mngqibisa, Enhancing Care Foundation

Zainab Mohamed, Groote Schuur Hospital

Jack Moodley, University of KwaZulu-Natal

Mohammed Moosa, Stellenbosch University

Diphale Mothabeng, University of Pretoria

Herman Motswaledi, University of Limpopo

Nombeko Mshunqane, University of Pretoria

Khanyi Msomi, University of KwaZulu-Natal

Daniel Murokora, Uganda Women's Health Initiative

Shingai Mutambirwa, Sefako Makgatho Health Sciences University Saloshini Naidoo, University of KwaZulu-Natal 
Pradeep Navsaria, University of Cape Town/Groote Schuur Hospital Duduzile Nsibande, South African Medical Research Council

Charles Parry, South African Medical Research Council

Robert Pattinson, University of Pretoria

Velisha Perumal, University of KwaZulu-Natal

Audrey Pettifor, University of North Carolina

Letitia Pienaar, University of South Africa

Marcel Post, University of Groningen

Sarah Rayne, University of the Witwatersrand

Andrew Redfern, Stellenbosch University

Annette Regan, Curtin University

Stephen Reid, University of Cape Town

Gary Reubenson, University of the Witwatersrand

Natasha Rhoda, University of Cape Town

Guy Richards, University of the Witwatersrand

Juergen Rockstroh, University of Bonn

Reitze Rodseth, University of KwaZulu-Natal

Christine Rogers, University of Cape Town

Shobna Sawry, University of the Witwatersrand

Neshaad Schrueder, Stellenbosch University

Chris Scott, University of Cape Town

Riaz Seedat, University of the Free State

Goodman Sibeko, University of Cape Town

Daniel Sifrim, Queen Mary University of London

Simon Stewart, University of Adelaide

Elmin Steyn, Stellenbosch University

Kebashni Thandrayen, University of the Witwatersrand

Gerhard Theron, Stellenbosch University

David Thomson, University of Cape Town

Sandie Thomson, University of Cape Town

Niki van Niekerk, University of Cape Town

Christo van Rensburg, Stellenbosch University

Sithembiso Velaphi, Chris Hani Baragwanath Hospital and University of the Witwatersrand

Klaus von Pressentin, Stellenbosch University

Morne Vorster, Tygerberg Hospital

Piet Wessels, University of the Witwatersrand

Dagmar Whitaker, Private practice

Tracey Wiggill, National Health Laboratory Service

Charles Wiysonge, Stellenbosch University

Virginia Zweigenthal, University of Cape Town

\section{CME guest editors and authors}

As editor of CME and SAMJ, I would like to thank all the guest editors and authors for their truly outstanding contributions to CME during 2018. This is much appreciated, particularly in the face of increasingly heavy clinical and teaching loads.

\section{Bleeding disorders}

Guest editor

$\mathrm{N}$ Alli, University of the Witwatersrand and National Health

Laboratory Service

\section{Authors}

N Alli, University of the Witwatersrand and National Health

Laboratory Service

J Vaughn, University of the Witwatersrand and National Health

Laboratory Service

S Louw, University of the Witwatersrand and National Health

Laboratory Service

E Schapkaitz, University of the Witwatersrand and National Health

Laboratory Service

J Mahlangu, University of the Witwatersrand and National Health
Laboratory Service

S Moodly, University of the Witwatersrand and National Health

Laboratory Service

M Patel, University of the Witwatersrand

\section{Lipidology}

Guest editor

N Ntusi, University of Cape Town

Authors

D J Blom, University of Cape Town

D Brozin, University of the Witwatersrand

F J Raal, University of the Witwatersrand

J A Rusch, University of Cape Town and National Health Laboratory Service

C L Hudson, University of Cape Town and National Health Laboratory Service

A D Marais, University of Cape Town and National Health

Laboratory Service

\section{Perioperative medicine and anaesthetics}

\section{Guest editor}

N Ntusi, University of Cape Town

Authors

L du Toit, Groote Schuur Hospital

T Biesman-Simons, Groote Schuur Hospital

N Levy, West Suffolk Hospital, UK

J A Dave, Groote Schuur Hospital

E Neethling, University of Cape Town and Red Cross War Memorial

Children's Hospital

F Roodt, University of Cape Town and Red Cross War Memorial

Children's Hospital

C Beck, Frere Hospital, Cecilia Makiwane Hospital and Walter

Sisulu University

J L C Swanevelder, University of Cape Town and Red Cross War

Memorial Children's Hospital

K Bester, University of Cape Town

H Meyer, University of Cape Town

M Crowther, University of Cape Town

R Gray, University of Cape Town

\section{Paediatric asthma}

\section{Guest editor}

R Masekela, Inkosi Albert Luthuli Central Hospital and University of KwaZulu-Natal

\section{Authors}

R Masekela, Inkosi Albert Luthuli Central Hospital and University of KwaZulu-Natal

C L Gray, University of Cape Town

R J Green, Steve Biko Academic Hospital and University of Pretoria

A I Manjra, Private practice

F E Kritzinger, Netcare Christiaan Barnard Hospital and

Stellenbosch University

M Levin, University of Cape Town and Red Cross War Memorial

Children's Hospital

H Zar, University of Cape Town and Red Cross War Memorial

Children's Hospital

S M Risenga, University of Limpopo

O P Kitchin, Private practice

D A White, Charlotte Maxeke Academic Hospital and University of the Witwatersrand

G Davis, Private practice

P Goussard, Stellenbosch University 
A Jeevanathrum, Steve Biko Academic Hospital and University of Pretoria

S Kling, Stellenbosch University

T C Gray, Stellenbosch University

J Morrison, Stellenbosch University

A Vanker, University of Cape Town and Red Cross War Memorial

Children's Hospital

A S Puterman, Private practice

D Rhode, Private practice

E W Zöllner, Stellenbosch University

P de Waal, University of the Free State

P M Jeena, Inkosi Albert Luthuli Central Hospital and University of KwaZulu-Natal

M Annamalai, Private practice

V Naidoo, Inkosi Albert Luthuli Central Hospital and University of KwaZulu-Natal

A van Niekerk, Steve Biko Academic Hospital and University of Pretoria

D Hawarden, Groote Schuur Hospital and University of Cape Town $S$ Emanuel, Private practice

H Katz, Allergy Live

\section{Tattoos}

Guest editors and authors

R J Lehloenya, Groote Schuur Hospital and University of Cape Town R M Ngwanya, Groote Schuur Hospital and University of Cape Town T Isaacs, Groote Schuur Hospital and University of Cape Town

\section{'Red flags' in pregnancy}

\section{Guest editor}

J Moodley, Woman's Health and HIV Research Group and University of KwaZulu-Natal

\section{Authors}

J Moodley, Woman's Health and HIV Research Group and University of KwaZulu-Natal

N Mayat, Queen Nandi Hospital

N F Moran, KwaZulu-Natal Department of Health and University of KwaZulu-Natal

N C Ngene, Woman's Health and HIV Research Group and University of KwaZulu-Natal and Klerksdorp Hospital

P Soma-Pillay, Steve Biko Academic Hospital and University of Pretoria

J Anthony, Groote Schuur Hospital and University of Cape Town S D Mandondo, National Committee for the Confidential Enquiry into Maternal Deaths

S N Cebekhulu, Kalafong Provincial Tertiary Hospital and University of Pretoria

R C Pattinson, Medical Research Council and Infant Health Care Strategies Unit and University of Pretoria

$S$ Fawcus, University of Cape Town

G S Gebhardt, Stellenbosch University

\section{Bridget Farham}

Editor

ugqirha@iafrica.com

S Afr Med J 2019;109(1):4-6. DOI:10.7196/SAMJ.2019.v109i1.13839 